\title{
Factors affecting functional outcome after decompressive craniectomy performed for traumatic brain injury: A retrospective, cross-sectional study
}

Farid Khan

Aga Khan University, farid.khan@aku.edu

Arif Villani

Aga Khan University, arif.villani@aku.edu

Abdul Rehman

Aga Khan University, abdul.rehman@aku.edu

Muhammad Ehsan Bari

Aga Khan University, ehsan.bari@aku.edu

Follow this and additional works at: https://ecommons.aku.edu/pakistan_fhs_mc_surg_neurosurg

Part of the Neurology Commons, Neurosurgery Commons, and the Surgery Commons

\section{Recommended Citation}

Khan, F., Villani, A., Rehman, A., Bari, M. (2018). Factors affecting functional outcome after decompressive craniectomy performed for traumatic brain injury: A retrospective, cross-sectional study. Asian Journal of Neurosurgery, 13(3), 730-736.

Available at: https://ecommons.aku.edu/pakistan_fhs_mc_surg_neurosurg/154 


\title{
Asian Journal of An official publication of the Asian Congress of Neurosurgery (ASIANCNS) Neurosurgery \\ Home \\ Current issue Instructions Submit article
}

Asian J Neurosurg. 2018 Jul-Sep; 13(3): 730-736.

PMCID: PMC6159096 doi: [10.4103/ajns.AJNS 6 18]

PMID: $\underline{30283535}$

\section{Factors Affecting Functional Outcome after Decompressive Craniectomy Performed for Traumatic Brain Injury: A Retrospective, Cross-sectional Study}

\author{
Farid Khan, Arif Valliani, Abdul Rehman, ${ }^{1}$ and Muhammad Ehsan Bari \\ Department of Surgery, Aga Khan University Hospital, Karachi 74800, Pakistan \\ ${ }^{1}$ Department of Biological and Biomedical Sciences, The Aga Khan University, Karachi 74800, Pakistan \\ Address for correspondence: Dr. Muhammad Ehsan Bari, Department of Surgery, Section Neurosurgery, The Aga Khan University, P. \\ O. Box 3500, Stadium Road, Karachi 74800, Sindh, Pakistan. E-mail: ehsan.bari@aku.edu \\ Copyright : @ 2018 Asian Journal of Neurosurgery
}

This is an open access journal, and articles are distributed under the terms of the Creative Commons Attribution-NonCommercialShareAlike 4.0 License, which allows others to remix, tweak, and build upon the work non-commercially, as long as appropriate credit is given and the new creations are licensed under the identical terms.

\section{Abstract}

\section{Background:}

Factors affecting functional outcome after decompressive craniectomy (DC) performed for traumatic brain injury (TBI) remain poorly understood.

\section{Methods:}

We conducted a retrospective study of all patients who underwent primary DC for TBI at our hospital between 2010 and 2014. Multivariate regression analyses were used to determine the predictors of functional outcome and overall survival.

\section{Results:}

A total of 98 patients with severe $(n=81,82.6 \%)$ or moderate $(n=17,17.4 \%)$ TBI underwent primary DC and were included in this study. The 30-day and overall mortality rates were $15.3 \%$ and $25.5 \%$, respectively. At a median follow-up of 90 (interquartile range (IQR): 38-180) days, median Karnofsky Performance Status (KPS) and Glasgow outcome scale-extended (GOSE) scores were 50 (IQR: 20-70) and 5 (IQR: 3-7), respectively. Young age and severe TBI were predictors of mortality. Glasgow coma scale (GCS) score on discharge was a strong predictor of KPS and GOSE scores.

\section{Conclusion:}

Primary DC afforded an acceptable functional outcome (GOSE score $\geq 5$ ) in $45.9 \%$ of patients. Young age and lower GCS at presentation were associated with worse survival. GCS score on discharge was a strong predictor of functional outcome.

Keywords: Decompressive craniectomy, functional outcome, head injury, traumatic brain injury

\section{Introduction}


Traumatic brain injury (TBI) remains a major cause of morbidity and mortality worldwide.[1] According to estimates, TBI is the cause of disability in approximately 5.3 million persons living in the United States.[2] The direct and indirect cost of TBI in the United States is close to $\$ 60$ billion annually.[] ] In Australia, approximately 1000 patients sustain TBI annually, which eventually accounts for a lifetime cost of about $\$ 1$ billion.[4] Even for patients who are hospitalized with severe TBI, almost $60 \%$ are affected by serious disability or mortality.[] Given the dismal outlook for patients with severe TBI, efforts have been made to identify effective treatment modalities for such patients.

As the damage inflicted by trauma in most patients with TBI cannot be reversed, medical and surgical therapies are primarily directed at reducing secondary neuronal injury. Increased intracranial pressure (ICP) as a consequence of TBI can lead to compression of brain parenchyma, compromised cerebral perfusion, impaired CSF circulation, irreversible neuronal injury, and even brain herniation.[] ] To mitigate the detrimental consequences of increased ICP, several first-tier and second-tier measures have been recommended by the Brain Trauma Foundation.[7] In patients with severe TBI and elevated ICP that is refractory to medical management, decompressive craniectomy (DC) is sometimes performed to relieve ICP and to provide space for brain tissue to expand.[ㅁ]

Despite the theoretical promise of DC, its role in the management of patients with severe TBI and elevated ICP remains somewhat controversial. A Cochrane review published in 2006 concluded that performing DC in patients with severe TBI and elevated ICP does not improve functional outcomes.[]] Subsequently, the results of the DC in Diffuse TBI (DECRA) trial further reinforced this proposition. [10] Recent guidelines by the Brain Trauma Foundation did not recommend DC for the management of refractory intracranial hypertension in patients with TBI and diffuse injury.[]] Results of the randomized evaluation of surgery with craniectomy for uncontrollable elevation of intracranial pressure (ResCue ICP) trial showed that DC may provide possible benefits in terms of survival when used as a last resort as compared to medical management alone, although functional outcome may be slightly worse.[11]

Keeping the conflicting results from the DECRA[10] and ResCue ICP[11] trials in view, it seems likely that DC may afford a favorable functional outcome in carefully selected patients with TBI.[] Given that performing randomized trials in patients with TBI is technically challenging,[12] results from observational studies have been given more weightage in this regard.[13] In the present study, the aim was to ascertain factors that were predictive of a favorable functional outcome among patients who underwent DC for TBI at our institution.

\section{Methods}

Our hospital is a 522-bedded, tertiary care center located in an urban city of a developing country with an estimated population of over 23.5 million. After obtaining approval from the Institutional Ethics Review Committee, a retrospective, cross-sectional study was performed using the institutional medical records database. All files with an International Classification of Diseases, $9^{\text {th }}$ Revision-Clinical Modification diagnosis code for "TBI" and procedure code for "DC" were retrieved. Patients diagnosed with a TBI between 2010 and 2014 were included in the study. Using a predesigned, structured pro forma, each medical record was systematically reviewed, and data relating to demographics, clinical features, laboratory and radiologic findings, medical and surgical management, hospital stay, and follow-up visits were systematically collected. Time from injury to arrival in the emergency department and time interval between arrival in the hospital and DC were also recorded. Charlson comorbidity index (CCI) was calculated and recorded for each patient,[14] which was further categorized as $0,1,2$, or $\geq 3$. For all patients, findings of computed tomography (CT) were categorized as per the Marshal classification.[15] Revised Trauma Status (RTS) was recorded for each patient. The primary outcomes of interest were Karnofsky Performance Score (KPS) and Glasgow Outcome ScaleExtended (GOSE) at the last follow-up. 
Statistical Package for Social Sciences (SPSS) version 20.0 (IBM; New York City, NY, United States) was used for performing statistical analysis. Frequencies were calculated for qualitative variables, while mean (standard deviation) or median (interquartile range [IQR]) were computed for quantitative variables. Statistical tests included Chi-square or Fisher's exact test for comparison of proportions, Student's $t$-test for comparison of means, and Wilcoxon signed rank-sum test for comparison of median ranks. Multivariate logistic regression analysis was performed to determine the predictors of survival using a stepwise forward approach. Moreover, multivariate linear regression models were constructed to determine the predictors of KPS score and GOSE score (i.e., measures of functional outcome). For all comparisons, a $P<0.05$ was considered statistically significant.

\section{Results}

A total of 98 patients who underwent DC during the study period were included in this study. Surgical procedures were performed by seven different neurosurgeons.

\section{Patient characteristics}

The median age of individuals included in our study was 30 (IQR: $22-45)$ years and $63(64.3 \%)$ were male. Hypertension $(n=15,15.3 \%)$ and diabetes $(n=10,10.2 \%)$ were the most common comorbidities. Most patients had a CCI score of $0(n=80,81.6 \%), 1(n=10,10.2 \%)$, or $2(n=6$, $6.1 \%)$. TBI in most individuals was secondary to road traffic accident $(n=64,65.3 \%)$, fall from a height $(n=17,17.4 \%)$, or firearm injury $(n=8,8.2 \%)$. The median time interval between injury and arrival in the hospital was 1.5 (IQR: 1.0-2.4) hours. On arrival, median Glasgow coma scale (GCS) score of individuals was 5 (IQR: $4-7)$ and all patients had either severe $(n=81,82.6 \%)$ or moderate $(n$ $=17,17.4 \%$ ) TBI. Median heart rate, respiratory rate, and systolic blood pressure $(\mathrm{BP})$ were 74 (IQR: 62-98) beats/min, 24 (IQR: 8-28) breaths/min and 150 (IQR: 138-164) mm Hg, respectively. Median RTS on arrival for patients was 10 (IQR: 8-11). Systemic injuries were noted in 25 (25.5\%) patients. Findings on CT as per the Marshall classification were diffuse injury II $(n=3,3.1 \%)$, diffuse injury III $(n=7,7.1 \%)$, diffuse injury IV $(n=5,5.1 \%)$, and mass lesion $(n=83,84.7 \%)$. Subdural hematoma $(n$ $=59,60.2 \%)$, epidural hematoma $(n=23,23.5 \%)$, subarachnoid hemorrhage $(n=23,23.5 \%)$, and intraparenchymal hemorrhage $(n=4,4.1 \%)$ were the most common types of mass lesions. These results are summarized in Table 1.

\section{Table 1}

Characteristics of patients included in our study cohort $(n=98)$ 


\begin{tabular}{|c|c|c|}
\hline Characteristics & All subjects ( $n=98)$ & Subjects who died $(n=25)$ \\
\hline Age (median [IQR]) & $30(22-45)$ years & $48(30-66)$ years \\
\hline \multicolumn{3}{|l|}{ Sex, $n(\%)$} \\
\hline Male & $63(64.3)$ & $18(72.0)$ \\
\hline Female & $35(35.7)$ & $7(28.0)$ \\
\hline \multicolumn{3}{|l|}{ Co-morbidities*, $n(\%)$} \\
\hline None & $80(81.6)$ & $10(40.0)$ \\
\hline Hypertension & $15(15.3)$ & $8(32.0)$ \\
\hline Diabetes mellitus & $10(10.2)$ & $6(24.0)$ \\
\hline Others & $5(5.1)$ & $4(16.0)$ \\
\hline \multicolumn{3}{|l|}{$\mathrm{CCI}, n(\%)$} \\
\hline 0 & $80(81.6)$ & $12(48.0)$ \\
\hline 1 & $10(10.2)$ & $7(28.0)$ \\
\hline 2 & $6(6.1)$ & $4(16.0)$ \\
\hline$\geq 3$ & $2(2)$ & $2(8.0)$ \\
\hline \multicolumn{3}{|l|}{ Mechanism of injury, $n(\%)$} \\
\hline Road traffic accident & $64(65.3)$ & $14(56.0)$ \\
\hline Fall from height & $17(17.4)$ & $9(36.0)$ \\
\hline Firearm injury & $8(8.2)$ & $2(8.0)$ \\
\hline Hit by an animal & $7(7.1)$ & 0 \\
\hline Hit by an object & $2(2.0)$ & 0 \\
\hline Time from injury to arrival in hospital (median [IQR]) & $1.5(1.0-2.4) \mathrm{h}$ & $2.3(1.0-3.75) \mathrm{h}$ \\
\hline GCS on arrival (median [IQR]) & $5(4-7)$ & $5(3-7)$ \\
\hline \multicolumn{3}{|l|}{ Severity of TBI, $n(\%)$} \\
\hline Mild (GCS >12) & 0 & 0 \\
\hline Moderate (GCS 9-12) & $17(17.4)$ & $2(8.0)$ \\
\hline Severe $(G C S \leq 8)$ & $81(82.6)$ & $23(92.0)$ \\
\hline Heart rate (median [IQR]) & $74(62-98)$ & $96(82-118)$ \\
\hline Systolic blood pressure (median [IQR]) & $150(138-164)$ & $123(100-139)$ \\
\hline Respiratory rate (median [IQR]) & $24(8-28)$ & $22(8-28)$ \\
\hline RTS (median [IQR]) & $10(8-11)$ & $9(8-11)$ \\
\hline Pupillary reflex intact, $n(\%)$ & $64(65.3)$ & $16(64.0)$ \\
\hline Gag reflex intact, $n(\%)$ & $60(61.2)$ & $15(60.0)$ \\
\hline Systemic injuries, $n(\%)$ & $25(25.5)$ & $6(24.0)$ \\
\hline \multicolumn{3}{|l|}{ Marshall CT grade of TBI, $n(\%)$} \\
\hline Diffuse injury I & 0 & 0 \\
\hline Diffuse injury II & $3(3.1)$ & 0 \\
\hline Diffuse injury III & $7(7.1)$ & $2(8.0)$ \\
\hline Diffuse injury IV & $5(5.1)$ & $3(12.0)$ \\
\hline Mass lesion & $83(84.7)$ & $20(80.0)$ \\
\hline \multicolumn{3}{|l|}{ Types of mass lesion', $n(\%)$} \\
\hline Subdural hematoma & $59(60.2)$ & $20(80.0)$ \\
\hline Epidural hematoma & $23(23.5)$ & $6(24.0)$ \\
\hline Subarachnoid hemorrhage & $23(23.5)$ & $10(40.0)$ \\
\hline Intraparenchymal hemorrhage & $8(8.2)$ & $3(12.0)$ \\
\hline
\end{tabular}

Open in a separate window

\section{Management and outcome}

Median time interval between arrival in the hospital and start of surgery (i.e., DC) was 2.3 (IQR: 1.34.0) hours, while the median interval between injury and start of DC was 4.8 (IQR: 3.2-12.0) hours. The median preoperative GCS score for study individuals was 5 (IQR: 3-7). Preoperative management strategies included hyperventilation to a target partial pressure of carbon dioxide of $32 \mathrm{~mm} \mathrm{Hg}$ and use of mannitol (dose of $1 \mathrm{~g} / \mathrm{kg}$ ). Vasopressors were used (if necessary) to maintain an adequate systolic BP. Some patients received antiepileptic medications (levetiracetam or phenytoin) for control of seizures. Patients with manifestations of elevated ICP refractory to these measures were taken for DC. Unilateral frontotemporoparietal DC (hemicraniectomy) and bifrontal DC were performed in 75 (76.5\%) and $23(23.5 \%)$ patients, respectively. In all patients, a question mark incision was given to raise flap, and a wide craniectomy was performed. In case of bilateral DC, a coronal incision was given, and a strip of bone was left in place over the superior sagittal sinus. Durotomy was performed in 
all cases, while duroplasty was performed in 58 (59.2\%) cases using pericranium and surgical. The median number of days spent in the intensive care unit was 5 (IQR: 3-8) days with a median length of total hospital stay of 17 (IQR: 9-28) days.

Infectious and noninfectious complications occurred in $28(28.6 \%)$ and $13(13.3 \%)$ patients as mentioned in Table 2. The 30-day mortality rate in our study cohort was $15.3 \%$ [ Figure 1], while on a long-term follow-up, a total of $25(25.5 \%)$ patients died. Median GCS score for patients at discharge was 9 (IQR: 4-12). Cranioplasty was performed in 68 (69.4\%) patients after a median period of 80 (IQR: 42-120) days. At a median follow-up of 90 (IQR: 38-180) days, median KPS and GOSE scores were 50 (IQR: 20-70) and 5 (IQR: 3-7), respectively.

Table 2

Interventions and outcome of study subjects $(n=98)$ 
Factors Affecting Functional Outcome after Decompressive Craniectomy Performed for Traumatic Brain Injury: A Retrospective, Cross-s...

\begin{tabular}{|c|c|}
\hline Parameters & Results \\
\hline \multicolumn{2}{|l|}{ Interventions } \\
\hline Door-to-surgery time (median [IQR]) & $2.3(1.3-4.0) \mathrm{h}$ \\
\hline Injury-to-surgery time (median [IQR]) & $4.8(3.2-12.0) \mathrm{h}$ \\
\hline Preoperative GCS (median [IQR]) & $5(3-7)$ \\
\hline \multicolumn{2}{|l|}{ Type of DC performed, $n(\%)$} \\
\hline Frontotemporoparietal DC & $75(76.5 \%)$ \\
\hline Bifrontal DC & $23(23.5 \%)$ \\
\hline Duration of surgery (median [IQR]) & $3.7(3.0-4.2) \mathrm{h}$ \\
\hline Estimated blood loss (median [IQR]) & $800(500-1200) \mathrm{ml}$ \\
\hline Length of stay in ICU (median [IQR]) & $5(3-8)$ days \\
\hline Overall length of stay in hospital (median [IQR]) & 17 (9-28) days \\
\hline Vasopressor support, $n(\%)$ & $30(30.6)$ \\
\hline Tracheostomy, $n(\%)$ & $59(60.2)$ \\
\hline Gastrostomy, $n(\%)$ & $30(30.6)$ \\
\hline \multicolumn{2}{|l|}{ Outcome } \\
\hline Overall mortality & $25(25.5)$ \\
\hline Interval from TBI to death (median [IQR]) & $9(3-47)$ days \\
\hline Complications, $n(\%)$ & $35(35.7)$ \\
\hline \multicolumn{2}{|l|}{ Infectious complications*, $n(\%)$} \\
\hline Pneumonia & $7(7.1)$ \\
\hline Urinary tract infection & $7(7.1)$ \\
\hline Wound infection & $6(6.1)$ \\
\hline CNS infection & $5(5.1)$ \\
\hline Other & $2(2.0)$ \\
\hline \multicolumn{2}{|l|}{ Noninfectious complications*, $n(\%)$} \\
\hline Hydrocephalus & $9(9.2)$ \\
\hline Subdural hematoma & $6(6.1)$ \\
\hline Expansion of contusion & $5(5.1)$ \\
\hline Deep vein thrombosis & $3(3.1)$ \\
\hline GCS on discharge & $9(4-12)$ \\
\hline Cranioplasty, $n(\%)$ & $68(69.4)$ \\
\hline DC-to-cranioplasty time (median [IQR]) & $80(42-120)$ days \\
\hline
\end{tabular}

Open in a separate window 


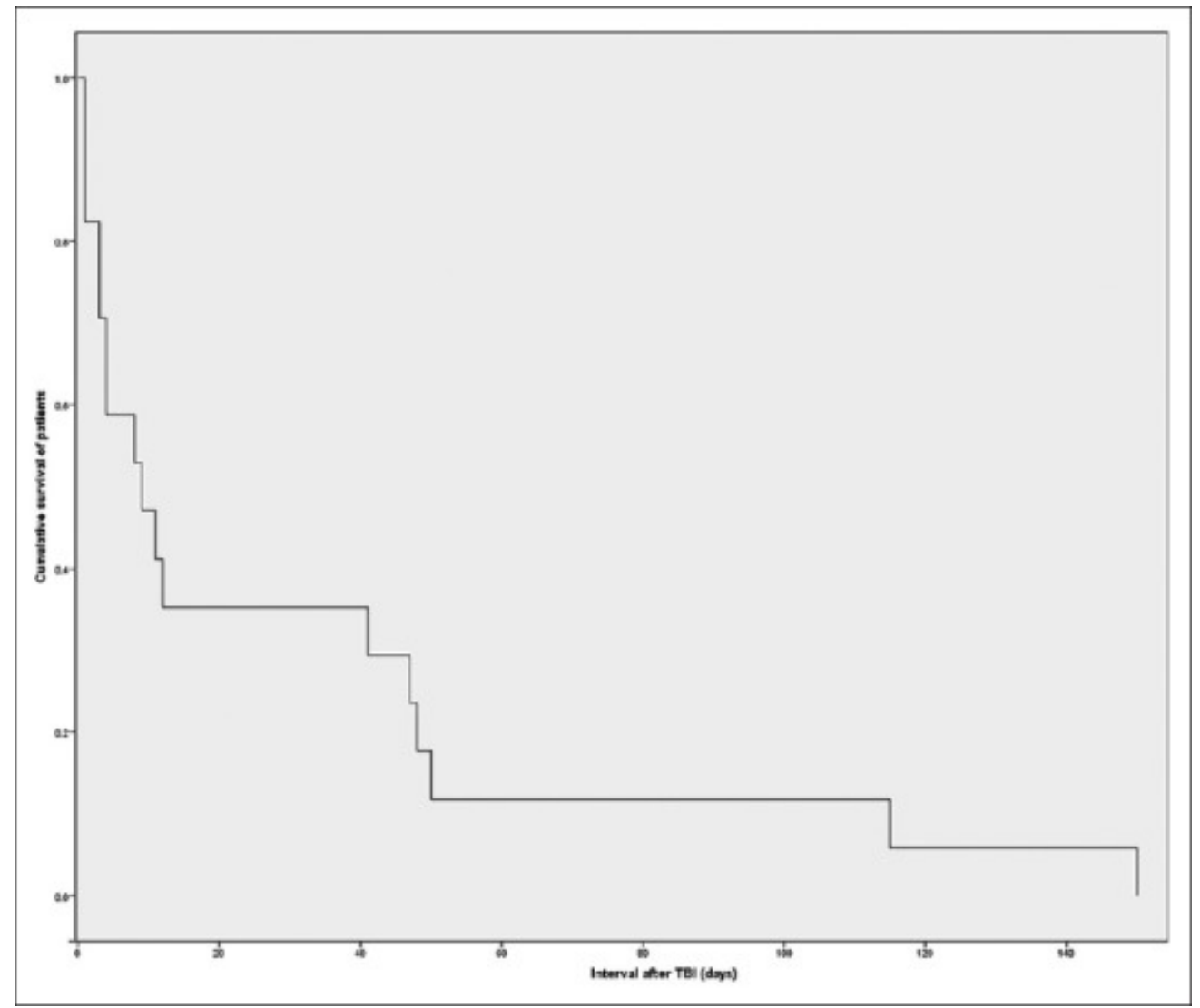

\section{Figure 1}

Kaplan-Meier survival curve depicting the survival of patients (Y-axis) in our cohort over time (X-axis)

\section{Factors affecting outcome}

Univariate analysis was performed using Chi-square or Fisher's exact test and variables were categorized for this purpose as follows age (0-39 years, 40-64 years, and $\geq 65$ years), comorbidities (none, one, or more than one), severity of TBI (moderate or severe), TBI-to-arrival in hospital interval $(<1.5 \mathrm{~h}, 1.5-3 \mathrm{~h}$, or $>3 \mathrm{~h}$ ), RTS ( $<9$ or $\geq 9)$, mechanism of injury (fall from height, firearm injury, hit by an animal, hit by an object, or road traffic accident), GOSE score $(<5$ or $\geq 5)$, and KPS score $(0 \%-20 \%$, $21 \%-60 \%$, or $61 \%-100 \%$ ). Univariate analysis revealed that GOSE score was significantly affected by age group, severity of TBI, RTS, and TBI-to-arrival in hospital interval. KPS score was significantly affected by age group, presence of comorbidities, and severity of TBI and RTS. Overall mortality was significantly associated with age, presence of comorbidities, and severity of TBI. The $P$ values for these analyses are provided in Table 3. Multivariate logistic regression analysis showed that young age (odds ratio: 16.78) and severe TBI (odds ratio: 90.91) were the only two statistically significant predictors of mortality. Multivariate linear regression analysis revealed that duration of surgery $(P=$ $0.043)$, length of stay in hospital $(P=0.008)$, and GCS on discharge $(P<0.001)$ were predictors of KPS score. Likewise, multivariate linear regression analysis showed that GCS on discharge $(P<0.001)$ was the only predictor of GOSE score. These models accounted for $84.4 \%$ and $82.3 \%$ of variation in KPS and GOSE scores, respectively. 
Factors affecting functional outcome and overall mortality in our patients

\begin{tabular}{lc}
\hline Factors & $P^{*}$ \\
\hline \multicolumn{1}{c}{ Overall mortality } \\
\hline Age group & $0.001^{\dagger}$ \\
Presence of comorbidities & $0.031^{\dagger}$ \\
Severity of TBI & $0.034^{\dagger}$ \\
TBI-to-arrival in hospital interval & 0.290 \\
RTS & 0.879 \\
Mechanism of injury $\quad$ GOSE score & 0.181 \\
\hline \multicolumn{2}{c}{} \\
\hline Age group & $0.012^{\dagger}$ \\
Presence of comorbidities & 0.073 \\
TBI-to-arrival in hospital interval & $<0.001^{\dagger}$ \\
RTS & $0.046^{\dagger}$ \\
Mechanism of injury & $0.031^{\dagger}$ \\
\hline
\end{tabular}

\begin{tabular}{lc}
\hline \multicolumn{2}{c}{ KPS score } \\
\hline Age group & $<0.001^{\dagger}$ \\
Presence of comorbidities & $0.002^{\dagger}$ \\
Severity of TBI & $0.001^{\dagger}$ \\
TBI-to-arrival in hospital interval & 0.812 \\
RTS & $0.002^{\dagger}$ \\
Mechanism of injury & 0.173 \\
\hline${ }^{\dagger} P$ values obtained using $\chi^{2}$ or Fisher's exact test, 'Indicates \\
statistical significance (i.e., $P<0.05)$. TBI - Traumatic brain \\
injury, RTS - Revised trauma score; GOSE - Glasgow outcome \\
scale-extended, KPS - Karnofsky performance status
\end{tabular}

Open in a separate window

\section{Discussion}

In patients with TBI, neuronal injury and death secondary to the primary insult are irreversible. Secondary injury caused by raised ICP and cerebral edema can be potentially prevented and may provide an opportunity to salvage neurons and improve functional outcome.[16] First-tier and secondtier interventions have been proposed to reduce ICP and control secondary neuronal injury.[7] DC is a neurosurgical procedure in which decompression of the brain parenchyma is achieved by removing a piece of skull and opening the dura mater; this effectively reduces the ICP and theoretically can limit secondary neuronal injury.[17] DC can be performed as either an early therapeutic intervention as part of a multi-tiered management protocol of TBI or it can be considered as a last-tier intervention to reduce ICP in patients for whom all other therapeutic maneuvers have failed.[11]

In our study, 98 patients underwent DC for moderate or severe TBI and $45.9 \%$ had an acceptable functional outcome (i.e., GOSE score $\geq 5$ ). The overall mortality rate in our patient cohort was $25.5 \%$. These results are comparable to the results of the ResCue ICP trial.[11] In the ResCue ICP trial, the overall mortality in the surgical group $(n=202)$ was $30.4 \%$ and $32 \%$ of patients had a GOSE score of 
$\geq 5$. However, it is important to note that all patients underwent primary DC in our study and the median time interval between arrival in the hospital and start of DC was $2.3 \mathrm{~h}$. On the other hand, DC was performed as a last-tier intervention (i.e., secondary DC) in the ResCue ICP trial. Moreover, the proportion of patients with mass lesion (84.7\%) in our study was much higher than that of the ResCue ICP trial (20\%). This probably better represents the subset of patients with severe TBI who typically undergo DC in centers located in lower- to middle-income countries.[18]

A few peculiarities were also notable in our study cohort. The bulk of our study sample consisted of men $(64.3 \%)$, which may a reflection of the male-dominated nature of the local society.[19] All patients included in the study had moderate or severe TBI, which was expected as DC is not performed in cases of mild TBI. The median age of study individuals was 35 years and most had no comorbidities. These observations underscore the fact that TBI affects the healthy and most economically productive proportion of the society.[20] This also explains the observation that young age was a predictor of mortality in our study. Most previously published studies have implicated increasing age as a predictor of mortality after TBI. $[\underline{21}, \underline{22}, \underline{23}, \underline{24}]$ However, in our study cohort, elderly patients comprised only $8.2 \%$ of the sample and were under-represented. This precluded us from drawing any meaningful conclusions about the geriatric population. A possible explanation for this observation may be that our center is a tertiary care center and in the absence of a structured prehospital triage system, most such patients succumbed before reaching the hospital.[25] Another possible explanation is that the local population of our developing country has high fertility rates with limited life expectancy[를 and geriatric patients represent a small subset of the population at large (in contrast to the aging populations of most developed countries).

GCS at the time of discharge was a strong predictor of functional outcome (both KPS and GOSE scores) in our study. GCS after TBI has been used as a measure of severity of TBI and as such, patients with a lower GCS are likely to have more severe neuronal injury. This, in turn, translates into a worse functional outcome in the long run. In a study by Williams et al., immediate predecompression GCS score was noted to be a predictor of mortality.[27] In another report, Murray et al. found that eye and verbal components of the GCS score were most useful prognostic markers for functional outcome.[228] Moreover, in our study, KPS score was also influenced by duration of surgery and length of stay in the hospital. The duration of surgery may have an indirect impact on the degree of neuronal injury as in vitro studies have suggested that rapid expansion of swollen brain parenchyma can cause axonal stretch and injury. $[\underline{29}, \underline{30}, \underline{31}]$

There are a number of caveats to this study which should be kept in mind. First, our study was a retrospective study, and as such, the decision to perform DC was at the discretion of the treating neurosurgeon. Having said this, most neurosurgeons at our institution follow a protocol-based approach to the management of patients with TBI, which may have limited variability in patient selection. Second, we had a relatively small sample size $(n=98)$, which may have limited our ability to detect valid predictors of functional outcome and mortality. Despite this, we were able to identify a number of predictors of poor functional outcome (i.e., GCS at the time of discharge and duration of surgery). Third, our study was conducted at a single tertiary care center of a developing country, and we had a relatively small number of geriatric patients. Therefore, it remains uncertain whether the favorable outcome noted in our study cohort can be generalized to the geriatric population. Finally, most patients in our study underwent primary DC (i.e., within the first few hours of arrival to the hospital); and thus, the results of this study may not be applicable in cases where DC is used as a last-tier intervention (i.e., secondary DC). Despite these limitations, this study is noteworthy in that it included a large subset of patients with mass lesions, which was in contrast to the typical patient populations included in randomized trials of DC. $[10,11]$ This probably represents the subset of patients with severe TBI who typically undergo DC in centers located in lower- to middle-income countries.[18] Moreover, our study reported two measures of functional outcomes (KPS score and GOSE) for all patients and is one of the 
few studies to provide data on functional outcomes from a lower to middle income country. Overall, the results of our study suggest that severity of TBI, duration of surgery, and GCS at the time of discharge are strong predictors of long-term functional outcome.

\section{Financial support and sponsorship}

Nil.

\section{Conflicts of interest}

There are no conflicts of interest.

\section{References}

1. Ghajar J. Traumatic brain injury. Lancet. 2000;356:923-9. [PubMed]

2. Rutland-Brown W, Langlois JA, Thomas KE, Xi YL. Incidence of traumatic brain injury in the United States, 2003. J Head Trauma Rehabil. 2006;21:544-8. [PubMed]

3. Langlois JA, Rutland-Brown W, Wald MM. The epidemiology and impact of traumatic brain injury: A brief overview. J Head Trauma Rehabil. 2006;21:375-8. [uㅣㄹㅣ]

4. Myburgh JA, Cooper DJ, Finfer SR, Venkatesh B, Jones D, Higgins A Australasian Traumatic Brain Injury Study (ATBIS) Investigators. Epidemiology and 12-month outcomes from traumatic brain injury in Australia and New Zealand. J Trauma Acute Care Surg. 2008;64:854-62. [PubMed]

5. Maas AI, Stocchetti N, Bullock R. Moderate and severe traumatic brain injury in adults. Lancet Neurol. 2008;7:728-41. [PubMed]

6. Dixon CE, Clifton GL, Lighthall JW, Yaghmai AA, Hayes RL. A controlled cortical impact model of traumatic brain injury in the rat. J Neurosci Methods. 1991;39:253-62. [PubMed]

7. Carney N, Totten AM, O'reilly C, Ullman JS, Hawryluk GW, Bell MJ, et al. Guidelines for the management of severe traumatic brain injury. Neurosurgery. 2017;80:6-15. [PubMed]

8. Münch E, Horn P, Schürer L, Piepgras A, Paul T, Schmiedek P, et al. Management of severe traumatic brain injury by decompressive craniectomy. Neurosurgery. 2000;47:315-22. [PubMed]

9. Sahuquillo J, Arikan F. Decompressive craniectomy for the treatment of refractory high intracranial pressure in traumatic brain injury. Cochrane Database Syst Rev 2006. 2006 CD003983. [PubMed]

10. Cooper DJ, Rosenfeld JV, Murray L, Arabi YM, Davies AR, D'Urso P, et al. Decompressive craniectomy in diffuse traumatic brain injury. N Engl J Med. 2011;364:1493-502. [PubMed]

11. Hutchinson PJ, Kolias AG, Timofeev IS, Corteen EA, Czosnyka M, Timothy J, et al. Trial of decompressive craniectomy for traumatic intracranial hypertension. N Engl J Med. 2016;375:1119-30. [PubMed]

12. Maas AI, Roozenbeek B, Manley GT. Clinical trials in traumatic brain injury: Past experience and current developments. Neurotherapeutics. 2010;7:115-26. [MC free article] [PubMed]

13. Steyerberg EW, Mushkudiani N, Perel P, Butcher I, Lu J, McHugh GS, et al. Predicting outcome after traumatic brain injury: Development and international validation of prognostic scores based on admission characteristics. PLoS Med. 2008;5:e165. [PMC free article] [PubMed]

14. Charlson M, Szatrowski TP, Peterson J, Gold J. Validation of a combined comorbidity index. J Clin Epidemiol. 1994;47:1245-51. [PubMed] 
15. Maas AI, Hukkelhoven CW, Marshall LF, Steyerberg EW. Prediction of outcome in traumatic brain injury with computed tomographic characteristics: A comparison between the computed tomographic classification and combinations of computed tomographic predictors. Neurosurgery. 2005;57:1173-82. [PubMed]

16. Raghupathi R. Cell death mechanisms following traumatic brain injury. Brain Pathol. 2004;14:21522. [PubMed]

17. Bayir H, Clark RS, Kochanek PM. Promising strategies to minimize secondary brain injury after head trauma. Crit Care Med. 2003;31:S112-7. [PubMed]

18. Servadei F. Clinical value of decompressive craniectomy. N Engl J Med. 2011;364:1558-9. [PubMed]

19. Nasrullah M, Bhatti JA. Gender inequalities and poor health outcomes in Pakistan: A need of priority for the national health research agenda. J Coll Physicians Surg Pak. 2012;22:273-4. [PubMed]

20. Humphreys I, Wood RL, Phillips CJ, Macey S. The costs of traumatic brain injury: A literature review. Clinicoecon Outcomes Res. 2013;5:281-7. [PMC free article] [PubMed]

21. Hukkelhoven CW, Steyerberg EW, Rampen AJ, Farace E, Habbema JD, Marshall LF, et al. Patient age and outcome following severe traumatic brain injury: An analysis of 5600 patients. J Neurosurg. 2003;99:666-73. [PubMed]

22. Mosenthal AC, Lavery RF, Addis M, Kaul S, Ross S, Marburger R, et al. Isolated traumatic brain injury: Age is an independent predictor of mortality and early outcome. J Trauma Acute Care Surg. 2002;52:907-11. [PubMed]

23. Pompucci A, De Bonis P, Pettorini B, Petrella G, Di Chirico A, Anile C, et al. Decompressive craniectomy for traumatic brain injury: Patient age and outcome. J Neurotrauma. 2007;24:1182-8. [PubMed]

24. Susman M, Di Russo SM, Sullivan T, Risucci D, Nealon P, Cuff S, et al. Traumatic brain injury in the elderly: Increased mortality and worse functional outcome at discharge despite lower injury severity. J Trauma Acute Care Surg. 2002;53:219-24. [PubMed]

25. Shah AA, Rehman A, Sayyed RH, Haider AH, Bawa A, Zafar SN, et al. Impact of a predefined hospital mass casualty response plan in a limited resource setting with no pre-hospital care system. Injury. 2015;46:156-61. [PubMed]

26. Bhutta ZA, Hafeez A, Rizvi A, Ali N, Khan A, Ahmad F, et al. Reproductive, maternal, newborn, and child health in Pakistan: Challenges and opportunities. Lancet. 2013;381:2207-18. [PubMed]

27. Williams RF, Magnotti LJ, Croce MA, Hargraves BB, Fischer PE, Schroeppel TJ, et al. Impact of decompressive craniectomy on functional outcome after severe traumatic brain injury. J Trauma Acute Care Surg. 2009;66:1570-6. [PubMed]

28. Murray GD, Butcher I, McHugh GS, Lu J, Mushkudiani NA, Maas AI, et al. Multivariable prognostic analysis in traumatic brain injury: Results from the IMPACT study. J Neurotrauma. 2007;24:329-37. [PubMed]

29. Chung RS, Staal JA, McCormack GH, Dickson TC, Cozens MA, Chuckowree JA, et al. Mild axonal stretch injury in vitro induces a progressive series of neurofilament alterations ultimately leading to delayed axotomy. J Neurotrauma. 2005;22:1081-91. [PubMed]

30. Staal JA, Dickson TC, Gasperini R, Liu Y, Foa L, Vickers JC, et al. Initial calcium release from intracellular stores followed by calcium dysregulation is linked to secondary axotomy following 
transient axonal stretch injury. J Neurochem. 2010;112:1147-55. [PubMed]

31. Stiver SI. Complications of decompressive craniectomy for traumatic brain injury. Neurosurg Focus. 2009;26:E7. [PubMed]

Articles from Asian Journal of Neurosurgery are provided here courtesy of Wolters Kluwer -- Medknow Publications 